\title{
LA VEREDA DE GUIMARÃES ROSA Y LA VERDAD DE DOSTOIEVSKI: ESBOZO PARA UN ESTUDIO LITERARIO COMPARADO'
}

\author{
Dr. Biagio D'Angelo
}

...Casa da palabra, onde o silêncio mora, brasa da palabra, a hora clara, nosso Pai... (Caetano Veloso, A tercera margem do rio)

Não gosto do transitório, do provisorio, Gosto do Eterno. (Joâo Guimarães Rosa, entrevista en Revista Manchete, 11 de junio de 1963)

Guimarães Rosa ${ }^{2}$ representa, en mi experiencia de lector, una auténtica pasión literaria. Este preámbulo justificativo me parece necesario ya que no soy especialista de literatura brasileña y mi interés hacia la poética de la modernidad luso-brasileña nace justamente de una lectura casual, accidental, curiosa de una traducción italiana de Miguilim $^{3}$ y la consiguiente lectura de su obra máxima, Grande sertão, La impresión que

\footnotetext{
'Ponencia presentada al X Congreso Internacional FTEALC (Federación Internacional de Listudios sobre América Latina y Caribe), Moscui 25-29 hunio de 2001, en el simposio "El universo literaria de Gumarães Rosa", coordinado por la profesora Lélia Parteira Duarte, Pontificia Universidad de Minais Gerass (Brasil).

${ }^{3}$ Aunque autor fundamental no solamente de las letras brasileñas y conocido universalmente como uno de los más importantes renovadores del lenguiaje y de la forma narrauva del siglo XX, recordarnos aquí brevemente algunos datos esenciales de la carrera artísuca del autor de Grande sertâo: zondar. Joao Gumarāes Rosa naciố el 27 de junio de 1908, en la ciudad de Cordisburgo, Minais Gerais. Despuès de su ficenciatura en medicina, que consiguió en la universidad de Bélo Horizonte, trabajó en diversass ciưdades del interior del Brașil, demostrando siempre un profundo interés por la naturaleza, sobre todo, por la clasificación de animales y plantas, junto a la pasión hacia el estudio de lenguas extranjeras, gracias a que aprendió, de manera autodidacta, el ruso y el alemán. Én 1934 inició la carrera diplomàtica, trabajando muchos años en el extranjero: en Alemania durante la segunda guerra mundial, y después en Francia y en Colombia. En 1958, fuc ministro y contemporànearmente tuva el gran reconocimiento de la crituca como escutor geniat, gracias a la publicación en 1958 de una colección de cuentos, Corpo de baile, y de su novela mayor, Granto jertäo: veredas, Elegide miembro de Ja Academia Brasileira de Letras en 1967, murió este mismo año en Rio de janeiro.

'Se trata de la traducción de Edoarda Bizzarri (ediciones Feltrinelli, Milán, 1987), uno de los mas inspirados traductores de la obra de Guimaràes Rosa, cun quien zuvo un intercambio de correspondencia iluminante sebre ba comprensión de la poética rosiana y
} 


\section{Dr. Biagio D'Angelo}

dejaba este texto difícil, complejo, variadísimo, revelaba el mismo sobresalto ocurrido después de la lectura de Crimen y castigo, que había sido decisivo para que mi campo de trabajo fuera la literatura rusa. Además, la lectura de Grande sertão habia suscitado una constante e imprevista comparación entre los dos autores, debida a una sustancia sistemática de la pregunta existencial que se encontraba, de forma sorprendente, en la concepción artística de los dos novelistas. Esta intuición, inicialmente no sometida al trabajo objetivo del crítico, reveló, en el tiempo y en el ahondamiento del sujetó tratado, una fuente interesante de motivos e ideas relativos a una perspectiva de influencias del gran novelista ruso sobre la creación rosiana. Este artículo quiere ser simplemente un esbozo de ciertos problemas que una atenta lectura de las obras de Guimarães Rosa y Dostoievski propone.

La afirmación de Guimarães Rosa, extraída de la entrevista con Günter Lorenz, según la cual "Goethe nasceu no sertão, assim como Dostoievski, Tolstoj, Flaubert, Balzac", nos deja, por lo tanto, iniciar cautelosamente la comparación con Dostoievski, autor entre los más predilectos por el escritor brasileño. Cautelosamente, porque se trata de dos colosos de la literatura universal y podría parecer que un análisis comparativo, en la búsqueda de síntesis y semejanzas, arriesgue reducir la fuerza única e indiscutible de los dos escritores.

Por el contrario, la lectura en filigrana de la recepción, de parte de Rosa, del pensamiento filosófico y de un cierto imaginatio dostoievskiano, puede ser motivo de profundización del "magmático" material subyacente a la producción rosiana.

La atención solicitada, de parte de Dostoievski, a la "exposición" de problemas existenciales profundos, unida a una escritura innovadora monológica y dialógica, que había largamente interesado a un gran crítico como Bajtín, permite tomar en consideración otro juicio rosiano, Rosa sostenía, al respecto, que "no desde un punto de vista (puramente) filológico, sino desde un punto de vista metafísico, en el sertão $0^{6}$ se habla la lengua de Goethe, Dostoievski, Flaubert"? Tal afirmación resulta muy interesante

\footnotetext{
la conceperón de la vida y de la líteratura a través del complejo tejido rosiano. Támbién el prefacio al pequeño volúmen merecé ses citado, porque fue realizado por Antonio Tabucchi, uno de los escritores más finos de esta illtims década, profundo conocedor del mundo luso-brasileño

"Günter Lorenz, "Dialogo con Guimarães Rơsa", in Gumanäes Rasa. Fortuma mrilica, Rio de Janeiro, Crvilização Brasileira, 1983. p. 85.

De M.M. Bajún, será tomado en consideración Problemsas de lo poética de Dosloienstea, Cuadad de México, Fondo de Cultura Económica, 1988.

"Prefiero la versión brasileña a la castellana, ya que me parece intraducible una nalia de la cultura del Brasil, tan cica de significaciones e implicaciones como la palabra uilizada por Guimaräes Rosa.

"Citado en Oscar Lopes, Introducción a J. Guimaráes Rosa, Sagrarana, Rio de Janeiro, edi. José Olympio, 1976, p. XV; "*... no desde el punto de vista filológico sino del metafisjeo, en el sertón se habla la lengua de Goethe, Dostoievski y Flaubert, porque el

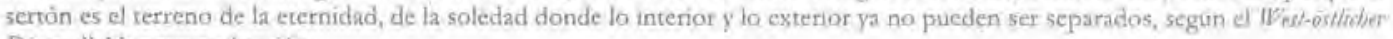
Ditant..," Nuestra rraducción.
} 


\section{LA VEREDA DE GUIMARÁES ROSA Y LA VERDAD DE DOSTOIEVSKI: \\ ESBOZO PARA UN ESTUDIO LITERARIO COMPARADO}

para percibir cómo, en nuestro caso, el autor ruso había intervenido en la formación y en la composición del corpus rosiano.

Afranio Coutinho ya había observado no sólo el sentimiento religioso omnipresente en la obra del brasileño, sino también la presencia de personajes que traían a la memoria a Dostoievski con sus seres humillados y ofendidos. Ellos son los mejores representantes de la esfera primordial del ser humano, como subraya Romano Guardini en su lectura de la obra de Dostoievski", y estar con el pueblo más humilde es quedarse en intima relación con los tratos más originales del ser, que nacen del "subsuelo", de la tierra. Se puede constatar que el paisaje regionalista o realista, con respecto a ambos casos, es superado pot una visión universal, cosmológica de la realidad. El pueblo humilde, ofendido, y la conexión con su raiz terrestre más profunda, representan dos elementos fundamentales del análisis dostoievskiano. Entre estos humillados se encuentran en la obra rosiana niños como Miguilim o Dito, o pre-seres, según la definición del crítico brasileño, una muchedumbre de existencias no suficientemente humanas, razonables, como Urigem, Joana, Xaviel, Gorgulho, Qustraz, Juegue, Chefe Zequiel, Jubileu Santos Oleos, Nhorinhá, todos personajes en la búsqueda de la redención y de la comprensión del sentido de la vida, todos héroes rebeldes, locos, suicidas, que "se apoderam da realidade, que agarram o destino pela garganta" ${ }^{10}$. Sin embargo, este lado oscuro del hombre, posee como extraordinario revez una luz que es el premio de su combate epopéyico, fiel, una "tercera margem do rio" "misteriosa e inalcanzable, en el desierto, no sólo metafórico, del sertão. No se puede evitar pensar en el escritor ruso, leyendo el siguiente juicio de Coutinho:

O ideal que informa a arte de Guimaraes Rosa è do bomem barmonioso. Ele sabia que o ser bumano não se desenvolve por igual, nele ficando sempre amplas áreas de sombra a serem iluminadas. Deonde a perversidade, o crime - os seres incompletos, que povoam sua fiçāo. ${ }^{12}$

Hacia la investigación y preferencia de tratar una materia poblada de seres incompletos, imperfectos, in fieri, se dirigia justamente la mirada del artista ruso. Otros personajes de Rosa parecen recordar a los de Dostoievski: seria suficiente pensar en Maria Mutema, símbolo de la purificación a través del pecado, que parece una versión sertaneja de Sonia, pureza conservada en pleno pecado, de Crimen y castigo. Por otra parte, los temas de la culpa y de la responsabilidad frente al Destino, de la sabiduria popular,

"Afranso Coutinho - Eduardo de Farra Coutinho, A literitira no Brasil, vol. 5, São Paulo, ed, Global, 1997.p. 481-82.

"Romano Guardint, El wmevero religiosa de Destoieusei, Buenos Aires, Emece, 1954.

"A. Couninho, op cit., p. 510

"Eistoy parafraseando el ritulo de uno de los cuentos más preciosos de Gumarăes Rosa. A teraera mergom do pa, incluído en Priweiras Estórios, publicado en 1962

"A. Courinho, op. cit., p. 483 


\section{Dr. Biagio D'Angelo}

espontánea, contra los efectos deletéreos de una inteligencia, abstracta y artificial son los argumentos de toda la obra de Guimarães Rosa, cuyo universalismo se encarna en varios momentos de Grande Sertão. Aquí la postura rebelde y violenta de personajes dostoievskianos como Stavroguin, Verjovenski y sobre todo Raskólnikov se ve concretizada en las ideas y en las dudas de Riobaldo sobre la existencia de Díos y del diablo. La dramática frase de Dostoevski, "Si Dios no existe, entonces todo es permitido", se podría escribir como epígrafe de la entera obra de Rosa. La violación de los límites, la superación de ciertas barreras que la naturaleza pone para el buen desarrollo de la percepción humana de la realidad, son problemas que angustian e inquietan la psique de Riobaldo en su monólogo largo y abarcador. Sin embargo Rosa, en las varias entrevistas otorgadas (Lorenz, Meyer-Clason, etc. ${ }^{13}$ ), también se muestra inquisitivo, aunque no dudoso, cuando, al tratar del sufrimiento de los más frágiles, afirma que el dolor infligido a los niños pueda revelarse como un obstáculo grave e insuperable para alcanzar la alegría de la fe: son ejemplos de esta reflexión la historia de los niños ciegos de Aleixo en Grande sertão y la muerte de Dito, en la parte más conmovedora de Corpo de baile. De hecho, el pequeño Miguilim al observar con curiosidad, miedo y ternura a su hermanito muerto constata en él "la misma cosa que cuando Dito estaba vivo", dándose cuenta de que la muerte es un aspecto esencial de la vida.

La muerte, la existencia del hombre, la presencia de Dios y la elección humana del diablo (el Peor, el Innombrable, el Oscuro), la intuición de un misterio insondable, representan en la filosofía rosiana, como en aquella dostoievskiana, las puertas de entrada hacia el conocimiento perfecto. La obra de Rosa sintetiza A. Coutinho - se realiza sub species perfectionis. ${ }^{14}$ Es un juicio muy apropiado: de hecho, la gran tesis central del monólogo de Riobaldo es la exposición de una única idea y de sus variantes; el predominio en el universo del sertão, es decir en el mundo, de la "gracia" milagrosa, operosa, activa, sobre la esclavitud de la "ley", del mal, del no ser.

EI sertão de Rosa es, para retomar un término preferido por Bajtín, un cronotopo paradigmático, porque éste "es el terreno de la eternidad, de la soledad, donde lo interior y lo exterior no pueden jamás estar separados", según lo que reporta Rosa mismo ${ }^{15}$. Es un sertão místico, un lugar de misterios y epílanías, como la ciudad de San Petersburgo que Dostoievski contribuyó a transformar en mito del alma y que utilizó, como lo hizo

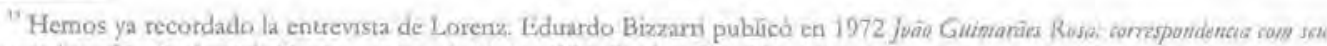

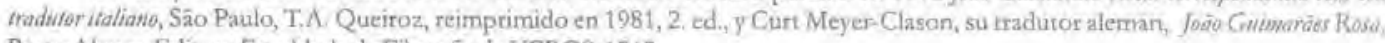
Porto Alegre, Editora Faculdade de Filosofia da UFRGS, 1969.

A. Coutinho, op cic, p. 480

"Véase nota n. 6
} 


\section{LA VEREDA DE GUIMARĀES ROSA Y LA VERDAD DE DOSTOIEVSKI: ESBOZO PARA UN ESTUDIO LITERARIO COMPARADO}

Rosa, para poder descubrir la cara escondida de las cosas, narrar lo inenarrable y desafiar la creación. El pacto con el diablo y la posibilidad del crimen o, aún más, del suicidio responden de forma distinta a la misma necesidad de conocimiento de la verdad. Como la configuración casi teatral de San Petersburgo, el sertāo de Rosa es ora particular, pequeño y próximo, ora universal $c$ infinito; este sertẫo es el mundo, según las palabras de Riobaldo, es un sertão que está dentro de la gente:

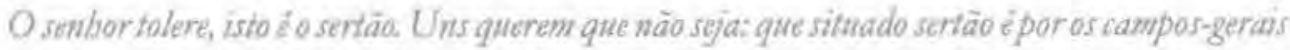
a fora a dentro, eles dizem, fin de rumo, terras altas, demais de Uruciua. Toleima. Para os de

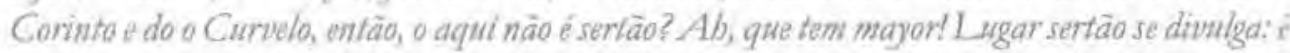
onde os pastas carecem de fechos; onde um pode torar dez, quinze leguas, sem topar con casa de morador; e onde criminoso vive seu Cristo Jesús, arredado do arrocho de autoridade. O Unwcitia vem dos montôes oestes. Mas, hoje, que na beira dele, tudo dâ fažendôes de fažendas, almargem de vargens de bom render, as vazantes; culturas que vão de mata en mata, madeiras de grosura, até ainda virgens dessas lá há. O gerais corre em volta. Esses gerais são sem tamanho. Enfint, cada um a que quer aprova, o senhor sabe; pão on pães, é questân de opiniōes... O sertão está em toda a parte".

Riobaldo, al abrirse el texto, introduce inmediatamente una situación dialógica reiterada a lo largo de todo el libro por las constantes referencias al interlocutor. Es una situación de dialogo virtual ya que se trata en realidad de un vasto monólogo ininterrumpido. Sin embargo, su monólogo es polifónico, en el sentido de que es dialógico y de que su vitalidad deriva de las reacciones distintas de su interlocutor a quien, como a lo largo de una confesión, Riobaldo se está abriendo y descubriéndose Para expresar la mímesis del alma universal de Riobaldo, Rosa logra crear un idioma nuevo que, aunque sea expresión de un único individuo, es esencialmente coral. El efecto coral se realiza linguísticamente en un rechazo de la sintaxis gramatical y a favor de la sintaxis expresiva. Rosa inventa nuevas estructuras, nuevas formas, nuevas palabras que tienen su origen en una lengua anterior más clara y apropiada, en la que se van mezclanda "con alto rendimiento estético", dice Coutinho, las palabras inventadas y su valor significativo arcaico. Se trata de una lengua en continua actividad creativa, infatigable mina de polionomasia, de combinaciones entre dialecto y arcaísmo, sin perder nunca su autenticidad, su expresividad polisémica. Rosa rechaza en un acto antihistórico un mundo en que la palabra ha perdido su peso y su ransparencia comunicativa. La desintegración de la lengua de su siglo no le es ajena, al contrario la

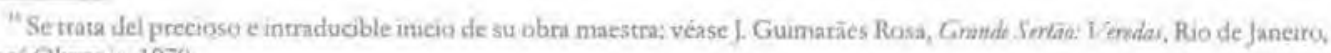
ed. José Olympto, 1970.
} 


\section{Dr. Biagio D'Angelo}

juzga, protestando contra su esterilidad. La palabra retoma su valor expresivo de transmisión de un mensaje filosófico. No se encuentra una revolución lingüistica tan radical en Dostoievskj, pero la lengua en sus novelas es igualmente un insurumento utilizado con el máximo espectro comunicativo, que va más allả de una clasificación banal de tealismo narrativo. En Dostoevski también se asiste a una disolución del sistema clásico de la novela, con una representación pluridimensional de la conciencia, que representa una de las modernidades absolutas de la obra dostoievskjana. Esta novedad del lenguaje narrativo dostoievskiano, al que Bajtín ha dedicado su interés critico, está presente también en la obra rosiana, pues ésta presenta un aspecto espiritual como proceso de purificación de los hombres a través de la circunstancia, de la peripecia y del viaje simbólico de la vida. Riobaldo, por ejemplo, necesita repetir su "travessía" personal para descubrir no tanto un sosiego o un consuelo derivado del encuentro con el Otro, cuanto una explicación a lo misterioso de la vida, sobre todo cuando el hombre experimenta la fascinación del pecado. El amor oscuro y tormentoso hacia Diadorim representa un encuentro único y enigmático, que cambia completamente la existencia de Riobaldo, de la misma manera que el encuentro y los diálogos con Sonia simbolizan el inicio de la purificación en el homicida Raskólnikov. Otro ejemplo es uno de los cuentos que Riobaldo confia a su interlocutor al principio de Grande sertāo, que indica un aspecto ulterior de la influencia dostoevskiana en el imaginario rosiano: se trata de la historia de Aleixo, modelo de exemplam cristiano, según la interpretación de $\mathrm{K}$. Rosenfield, pero también ejemplo de vida de santo y de conversión ${ }^{17}$. Aleixo es reconocido como hombre cruel que llega a su cumbre espantosa, matando con violencia aberrante y sin ningún motivo específico a un viejo mendicamente. Es evidente la referencia intertextual al asesinato de la vieja usurera en Crimen y sastigo. Después del delito, el castigo de Aleixo: sus cuatro niños se vuelven ciegos. Rosenfield escribe:

Neste golpe, ele reconbece o castigo divino nāo como algo meramente negativo, mas camo grafa que acorda swa misericordia.

La cercanía con el autor ruso, también en este caso, es significativa ${ }^{18}$.

Recurriendo a otra terminología bajtiniana, los personajes de Rosa son personajes-ideas, que presentan al lector y al mundo su concepción filosófica en la que podrían asimismo presentarse discontinuidades, rupturas, fragmentaciones, justamente por causa de su naruraleza dialógica. Riobaldo es, en este caso, familiar de Dimitri o Aliosha Karamazov, para los cuales la cuestión más espinosa y angustiante (pero

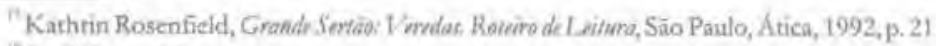

"In iblitem, p. 21.
} 


\section{LA VEREDA DE GUTMARÃES ROSA Y LA VERDAD DE DOSTOIEVSKI: ESBOZO PARA UN ESTUDIO LITERARIO COMPARADO}

tambjen aquella que rinde la vida como vaje iniciático y dramático hacia el verdadero conocimiento) es la existencia del mal, inevitablemente relacionada con el problema de la existencia de Dios. El jagungo Riobaldo es, por lo tanto, según la sintética definición de Coutinho, un héroe problemático, como problemáticos aparecen Ivan Karamazov o el príncipe Myshkin. El gran monólogo-diálogo de Riobaldo, narrador infatigable de mitos y cuestiones existenciales, posee su fuerza justamente en el hecho mismo de la narración y formula teóricamente cuál es la auténtica estructura de la novela, es decir, manifestación de los interrogantes en la búsqueda de una respuesta. Sólo un narrador excepcional como Riobaldo puedc afirmar, con sabiduria medieval, que aptender a vivir es lo mismo que vivir.

Se abre observa Arriguci una especie de escenario dramático propicio para la confrontacióny el debate de ideas, donde el mitos se vielve logos, escenificación dramática en la que la trama narrativa se traduce en el discurso intelectual".

El descubrimiento final de Riobaldo o el eterno interrogante de Miguilim participan de la recepción dostoievskiana de parte de Rosa (una especie de "antropofagia" rusa), probablemente un Dostoievski leído a la luz de las interpretaciones filosóficas de Nietzsche, Berdiaiev y del pensamiento ruso del principio del siglo XX. En este sentido, resulta impresionante la "cercania" espiritual de ambos novelistas. $\mathrm{La}$ analogia resulta también más sutil si tenemos en cuenta que para ambos autores las preocupaciones metafisicas son siempre vividas "carnalmente" o como ficción, es decir, como "travesia", y to como si fuera un tratado de mística apologética. Para Dostoievski, como también para Rosa, la metafísica (como eterno burbujear de las cuestiones eternas) es mucho más "physis" que "meta". En esta indagación en la "plyysis", concreta, visceral, en que el jagungo tiene que combatir para vencer, reside todo el vigor y la necesidad de operar en un registro lingüístico nuevo. Rosa, de la misma manera que Dostoievski, intenta desesperadamente captar, bajo la forma literaria de la escritura polifónica, lo inexpresable, lo indecible, lo infinito. Guimarães Rosa y Dostoievski han intuido que la búsqueda religiosa no es materia teológica, sino sentimiento pánico del universo, necesidad estructural del hombre, "radiosa aventura humana", como la define A. Coutinho, añadiendo palabras que pueden también leerse como adecuadas para Dostoievski, "a obra de Rosa, para quem a saiba ler, é um ato que busca a santitade do homem". Como el genial Carlos Drummond de Andrade observa en un poema dedicado a la figura del poeta brasileño, ${ }^{\text {". }}$.. ele mesmo ena / a parte de gente/ servindo

\footnotetext{
"Davi Arraguec Jr., "Mestzo y paradójico Gumarnies Rosa", ABC Culural, suplemento del periòdico ABC, Madrid, 14 de oetubre de 2000, p 10.
} 
de ponte / entre o sub e o sobre..." búsqueda religiosa, del "sub" y del "sobre" oscila la metafísica ("meta"- "física") que une a Rosa y a Dostoievski.

Dr. Biagio D'Angelo Pontificia Universidad Católica del Perú, Lima

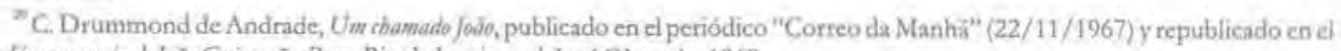
livto Em memoria de Joäs Guimaräes Rosa, Rio de Janeiro, ed. José Olympio, 1968. 